\title{
Colección de juegos de cartas de arquitectura. Siete recursos para iniciación, creatividad o experimentación avanzada
}

\author{
Collection of architecture card games. Seven resources \\ for initiation, creativity or advanced experimentation
}

\section{Resumen}

Autor:

Alberto Bravo de Laguna Socorro* alberto.bravodelaguna@ulpgc.es

* Universidad de Las Palmas de Gran Canaria
D siete juegos de cartas sobre arquitectura se conforma esta pequeña colección. Son juegos muy distintos que comparten una condición: ser además unos competentes recursos didácticos. Arquitectura y juego se cruzan entre ellos. El interés estará fundamentalmente en el conjunto, en la suma de opciones pedagógicas que ofertan. Desde la iniciación, a través de operaciones plásticas básicas de la arquitectura, como dibujar y construir, o simplemente observar sus atractivas ilustraciones, a la experimentación avanzada, con la escenificación de acciones análogas a la práctica profesional o la selección de opciones diversas para resolver proyectos mediante la combinación aleatoria o intencionada de unos mismos parámetros o reglas. Una actitud creativa y desprejuiciada ante esta colección posibilitará ponerla en valor, y reconocerla como un eficaz complemento formativo para el arquitecto.

Palabras clave: carta; juego; arquitectura; creatividad; experimentación.

\section{Abstract:}

This small collection is made up of seven sets of architecture cards. They are very different games that share a condition, as well as being competent didactic resources. Architecture and play are intertwined in them. The interest will be fundamentally in the set, in the sum of pedagogical options that they offer. From the beginning, through basic plastic operations of architecture, such as drawing and building or simply observing its attractive illustrations. Advanced experimentation, with the staging of actions analogous to professional practice or the selection of various options to solve projects through the random or intentional combination of the same parameters or rules. A creative and unbiased attitude towards this collection will enable it to be valued and estimate it as an effective training complement for the architect.

Keywords: card; game; architecture; creativity; experimentation. 


\section{Introducción}

Archicards, Scala, D'archis, House of Cards, 50 Urban Blocks, 50 Housing Floor Plans y Modulark son el objeto de estudio. Siete juegos de cartas sobre arquitectura escogidos por su aportación diferenciada como recurso didáctico, junto a una adecuada concepción gráfica que contribuye a su idoneidad pedagógica. Son juegos muy diferentes entre sí, creados entre 1956 y 2019, por autores ya consolidados (Babina, Eames, Ruiz, a+t, Straddle3) o noveles (Arquitectura a contrapelo), todos arquitectos. La arquitectura y el formato del naipe son los vínculos que los relacionan, a los que se podría añadir un tercero: su capacidad como complemento formativo en diferentes niveles, desde la iniciación al estado avanzado.

La primera aproximación al estudio de estos juegos se plantea en torno a dos términos: colección e interzona, (Celedón 2015, Vizcaíno 2015). Ambos términos establecen un inicial marco de estudio: colección por ser una recopilación de casos e interzona por la condición híbrida de estos. Sobre el primero, con la reunión de estos siete heterogéneos casos, se podría formar una colección:

El papel de la colección es encontrar y presentar un orden y una narrativa a través de la cultura material, la construcción de una versión adaptada del mundo infinito en la cual lo general se multiplica en una infinidad de casos particulares (Celedón,2015, p.47).

El valor coral prima al recopilar y seleccionarlos. El orden y la narrativa común lo aportan la arquitectura, el carácter didáctico y un elaborado diseño gráfico. Se podría argumentar que los integrantes de esta colección por sí mismos, vistos por separado, podrían no ser significativos en un ámbito académico. Ante esto se hace necesaria una observación: estos juegos "adquirirían valor desmontados de su contexto original para ser parte de una serie, en la cual las cosas pueden mirarse como parte de una idea universal más general" (Celedón, 2015, p.43).

\section{Sobre los juegos, textos de referencia}

El formato del naipe es el nexo en la selección de estos juegos diversos. Se han escogido por este formato común, y conscientes de las diferencias entre ellos. En la búsqueda de convergencias se analizan las características de juego, la intervención de la arquitectura y su implicación o capacidad didáctica en relación a esta disciplina. Los hemos observado, a diferentes niveles, como posibles herramientas docentes que, como valor añadido, además permiten "esclarecer conceptos lúdicos claves de la herramienta arquitectónica" (Arcos, 2015, p.36), si se hace un uso disciplinar de ellos. Los juegos tienen una concepción ambivalente: pueden ser utilizados con mayor o menor implicación formativa según lo que se pretenda de ellos, o el nivel del jugador.
Su implicación con la arquitectura puede ser tangencial o más profunda. Es opción del docente calibrar la intervención de la arquitectura en el desarrollo del juego, fundamentalmente en los considerados de iniciación: Archicards, Scala, D'archis y House of Cards.

El interés de estos juegos está en su reunión, como bien señala Bordes (2016): "coleccionar es crear una idea" (p.24). Este artículo tiene una concepción afín a los textos referenciados de Bordes Caballero ${ }^{1}$, aunque con una notoria diferencia del número de casos componentes. Al igual que en Bordes, "el criterio con el que he formado la colección expuesta es el de reunir el mayor número de ejemplos que reproduzcan la diversidad de sistemas existentes en la historia de los juguetes de construcción" (2016, p. 24). La diversidad de juegos dará valor a esta pequeña colección de solo siete recursos, adaptados a diferentes niveles en la formación arquitectónica del usuario; cada uno de ellos, en su nivel, facilita diferentes estrategias formativas.

Estas propuestas lúdicas podrán jugar un pape complementario en la formación de un futuro arquitecto, una alternativa a considerar. En este cometido, Archicards, Scala, D'archis y House of Cards, serán los recursos de iniciación, en tanto 50 Urban Blocks, 50 Housing Floor Plans y Modulark, serán los recursos avanzados, todos ellos insertos en un proceso formativo complejo que necesariamente habrá de ser protagonizado por la calidad, el rigor y la excelencia académica (Figura 1). En un entorno fundamentalmente digital, se pueden incorporar estos recursos analógicos como complementos formativos en los que se materializa lo expuesto por Alba (2018, p.20) acerca de la capacidad del juego de generar un ambiente propicio para el aprendizaje, que acompañe al orden obligado de percepciones y concepciones habituales en la formación, y lo abra hacia lo otro, lo inventado, lo imaginado, lo antes imperceptible e inconcebible, con el objeto de hacer más fácilmente entendibles los conceptos y poder impulsar y contagiar actitudes de trabajo en la introducción y el nivel avanzado.

Ante los juegos podría adoptarse la actitud creativa de Navarro Baldeweg (2016), expuesta en el catálogo de una exposición de la colección de juguetes de construcción de Juan Bordes, en el texto de "Una caja de cajas". Ante la observación de colecciones ordenadas, como cajas de herramientas, lápices de colores o carretes de hilo, Navarro (2016) reflexiona: "La contemplación de estos almacenes de elementos asociados a la elaboración de entidades más complejas es cautivadora, es causa de una excitación característica porque anuncia un territorio de expectativas, una promesa de infinitud" (p.9). Al ver estas colecciones, en Navarro se genera un territorio de expectativas que desafía y pone en marcha la curiosidad por aprender. Con la reunión de estos juegos de cartas, desde estas expectativas de aprendizaje compartidas, el jugador ensaya y experimenta con la arquitectura mediante diferentes acciones. Se desarrollarán operaciones básicas como dibujar y construir, o se

${ }^{1}$ Bordes Caballero ha reunido una valiosa colección de juegos y juguetes de dibujo y construcción, una numerosa agrupación que ha sido objeto de exposiciones y publicaciones en las que este autor destaca su componente didáctico, constituyendo una referencia de primer orden sobre la relación entre juego, arquitectura y enseñanza. 
podrán tomar decisiones intencionadamente análogas a las del arquitecto en su práctica. Una cuidada concepción gráfica de los componentes del naipe y el juego tendrá gran parte de la responsabilidad de fomentar e aprendizaje. El estar ilustrados con dibujos e imágenes resueltos con un esmerado y atractivo diseño visual, denota el interés de sus autores por una intervención activa de los componentes gráficos en sus propuestas de juego.

Interzona sería el otro término adecuado para ubicar estas cartas. Vizcaíno (2015) lo define como una "superposición de incumbencias, cruces entre arquitectura, arte $y$ diseño, pensamientos y materialidades desprejuiciadas (...) interzonas, espacios fronterizos de índole formativo" (p.2). Arquitectura, arte y diseño se cruzan también en diferentes dosis en la composición de los juegos. Estos cruces exigen un cierto desprejuicio al ser analizados en el campo académico, en el que sería previsible partir de una prejuiciada posición ante ellos, según la definición de prejuicio en la RAE: "opinión previa y tenaz, por lo general desfavorable, acerca de algo que se conoce mal" (RAE, 2020). Es notoria la importancia que tiene el juego y el juguete en el aprendizaje, pero, en consonancia con la definición de interzona, como pensamientos y materialidades desprejuiciadas, también en la interpretación de los juegos podría darse la prejuiciosa actitud de considerarlos como temas menores o intrascendentes, o de poca entidad para ser tratados en un entorno académico. Como bien escribe Bordes (2011) "(...) si nos desviamos de la enseñanza oficial, si revisamos las opciones minoritarias y marginales, descubrimos un germen de libertades que indudablemente aflora convertido en imagen del mundo moderno" (p.50). Las cartas, desde su posición marginal, también son capaces de sugerir una reflexión disciplinar sobre arquitectura, centrada en su índole formativa. Aun estando en una posición fronteriza, en una interzona entre juego y arquitectura, estas cartas ofertan su capacidad didáctica ubicada entre la diversión y la seriedad.

Hay numerosos casos precedentes de juegos y juguetes diseñados por arquitectos, muchos de ellos en consonancia con su obra. Una gran cantidad de autores ha prestado atención a las relaciones entre juego, juguete y arquitectura. Se han escrito múltiples teorías que enlazan juego y educación, por autores reconocidos como Fingermann, Claparéde, Spencer, Hall, Groos, Carra o Freud. En sus contenidos se desarrollan en profundidad interacciones entre juego y proyecciones sociales, recreo educativo, resurgimiento de tendencias atávicas, función biológica, catarsis de tendencias antisociales o su interpretación psicoanalítica. Valga la tesis de Gutiérrez (2004) como una muestra de las múltiples interpretaciones sobre juego y aprendizaje, sobre la trascendencia del juego en la sociedad y su compleja implicación en el comportamiento humano. En las diversas propuestas de las vanguardias del siglo XX se produjo un excelente campo de cultivo de estas teorías. Propuestas ubicadas en "el periodo de entreguerras, surgen desde la inquietud por sincronizar ciertas preocupaciones artísticas (innovadoras, revisadoras o aditivas), nuevas ideas sociales y renovadoras teorías pedagógicas; con un alto grado de libertad" (Gutiérrez, 2004, p.13), que atendían a puntos clave comunes, como "la semántica y el predominio conceptual y simbólico
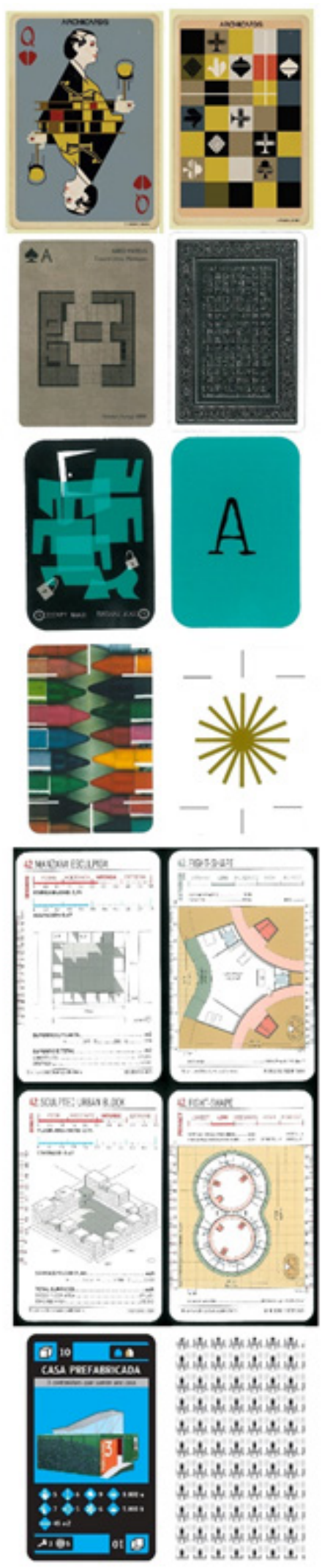

Figura 1: Selección aleatoria de cartas de los siete juegos. Cara y revés

Fuente: Babina (2020), Arquitectura a contrapelo (2020), Ruiz (2020), Eames (1986) Aplust (2020), a+t (2017), a+t 
de su lenguaje, las acciones plásticas experimentadas, la escenificación y en especial, el valor del reciclaje y la manipulación" (Sánchez, 2015, p.104). Los juegos de cartas seleccionados son, en cierta medida, deudores de estos precedentes de las vanguardias. De esos puntos clave que intervienen en ellos, destacarán la experimentación mediante acciones plásticas básicas, como dibujar y construir, y la escenificación de operaciones propias del proyecto de arquitectura, como combinar, componer, conjuntar, acordar o negociar, reforzadas con el empleo de un vivaz imaginario arquitectónico en las ilustraciones. Dibujar, construir y escenificar el proyecto serán, además, los ingredientes fundamentales de su condición didáctica.

Unos textos de referencia recopilados aportan reflexiones y pautas para elaborar el discurso compartido de la colección. Con ellos se compone un tramado de conceptos y propiedades que la fundamentan. En el primer texto, Mara Sánchez (2015) se cuestiona cómo interactúan juego y arquitectura:

Las dos preguntas fundamentales sobre la relación entre e juego y la arquitectura son: ¿Es el juego una manifestación, entre otras, del hecho arquitectónico? $\mathrm{O}$, por el contrario, ¿pensamos que la arquitectura es la parte creadora en la que se desarrolla la actividad lúdica del ser humano? Es difíci posicionarse ante solo una de las dos cuestiones planteadas, ya que la arquitectura se puede desarrollar como juego y en el juego, y, aunque pueden parecer mensajes contradictorios, en la arquitectura de nuestro tiempo vemos cómo estas relaciones están en constante aparición y desaparición, ya sea de forma conjunta o separada: las fronteras entre el juego y la creación arquitectónica se encuentran borrosas (p. 103).

Estos naipes arquitectónicos se sitúan en esas fronteras borrosas, una interzona, como ya señalábamos. En esta situación intermedia, para el desarrollo de esa parte creadora, cada juego tendrá una condición complementaria; esto hará que el interés se centre en la suma, una conjunción que incorporará cualidades tomadas de la arquitectura, que irán desde lo formal a lo constructivo o lo compositivo, entre otros, y en niveles de profundidad diferentes, adaptados al jugador.

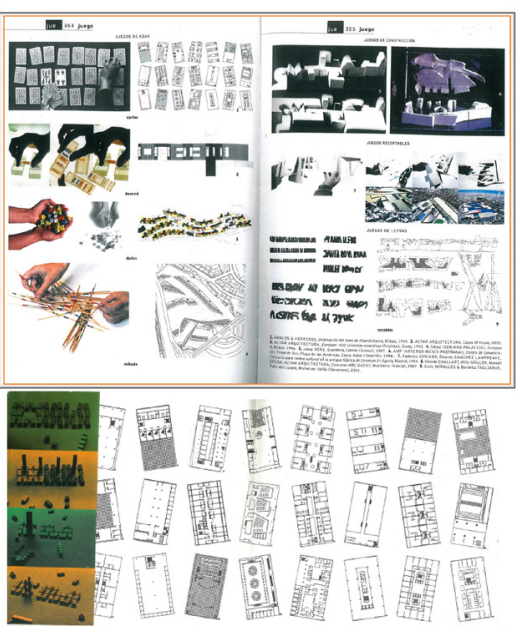

Figura 2: Arquitectura y juegos de azar, recortables, de letras y de construcción, como dominó, dados, mikado o scrabble, entre otros, en el diccionario Metápolis. Imágenes sobre el juego de cartas y el proyecto para Abandoibarra de Abalos y Herreros, 1994

Fuente: Gausa et al. (2002, pp.354-355) Bernardó (1997, p.235)
Del diccionario Metápolis de Arquitectura avanzada se extrae otro texto. En este, José Morales define el término juego vinculándolo a la arquitectura: "E proyecto es ese acto de conjuntar la diversidad de modo impredecible. Quizás a alguien se le ocurra que esto tiene que ver con cierta imagen de cómo se desarrolla el juego. (...) Se trata de un juego que formula sus nuevas leyes en cada tirada, en cada jugada" (Gausa et al., 2002, p. 352). También en Metápolis se reúnen siete proyectos seleccionados por su relación estratégica con diferentes juegos: cartas, dominó, dados, juegos de construcción, juegos recortables, juegos de letras o scrabble. Los proyectos y juegos asociados comparten cualidades formales, compositivas, estrategias en procesos y materializaciones. La ordenación del área de Abandoibarra, Bilbao, 1994, de Ábalos\&Herreros es el proyecto ligado al juego de cartas. En esta intervención se juega con diversas combinaciones compositivas de módulos de edificaciones repetidos, contenidos en un mismo perímetro de planta rectangular. Ábalos\&Herreros señalan al respecto: "no es casual por tanto la referencia al juego -en los Lego, en las cartas-, al azar controlado que implican los juegos en cuanto a sistemas y reglas eficaces por atractivas y solo parcialmente previsibles", en esta propuesta para Abandoibarra se trata "de ligar referencias y contextos mixtos, de injertar imágenes históricas en productos híbridos y hacerlos funcionar simultáneamente" (Bernadó, 1997, p. 235). El proyecto se ordena con una combinación de formas colocadas según un juego reglado, con una intervención controlada del azar, dos componentes que permiten a Metápolis establecer esta analogía con el juego de naipes (Figura 2). Valga como muestra lo que señala Arnau (2000), en otro diccionario de arquitectura:

El juego es una forma de representación (...) El juego configura así una forma de vida activa y representativa, libre y cargada de significado, que invita al arquitecto a proveer una respuesta asimismo lúdica, imaginativa y adecuada a sus instancias ( $p$ 138).

Para Arnau, el juego va a formar parte de la actividad de arquitecto, como en tantas otras actividades humanas. Será una forma de representación en la que el significado de sus actos trasciende su sentido inmediato, y en el caso de la arquitectura será eminentemente social.

Otro texto de referencia es "Cajas, dados, naipes.. Notas sobre una conversación con Anne Griswold Tyng" (Juárez, 2003). Se trata de una entrevista a Anne Tyng, colaboradora de Louis Kahn. El entrevistador lleva una pequeña "baraja" con proyectos de Kahn (Figura 3). Las cartas se despliegan aleatoriamente ante la entrevistada. Para el autor de la entrevista este conjunto de imágenes que se entremezclan sobre el tapete deviene en una alegoría del imaginario arquitectónico de Kahn, una radiografía mental del arquitecto, que relacionará en su texto con la forma en que acometía sus proyectos:

(...) Esta entrevista tuvo lugar en su casa-estudio de Filadelfia habiéndose preparado de antemano un pequeño dossier que recogía dibujos de plantas de Louis Kahn de algunos proyectos claves de estos años cincuenta. Esta pequeña "baraja" que estuvo sobre la mesa a lo largo de aquel rato de conversación que aquí se transcribe constituye una pequeña radiografía mental de Kahn -de las muchas que se podrían establecer y se publica conjuntamente con el texto con la finalidad de hacer posible al lector no familiarizado con dichos proyectos establecer sus propias conexiones. Como dados caídos sobre el tapete de una mesa, los bloques o cajas que constituyen 
estos proyectos adquieren una singular belleza. (...) Entre lo ordenado y lo aleatorio, y esta síntesis nos revela algo profundo y apasionante de su modo de proyectar. (p. 91)

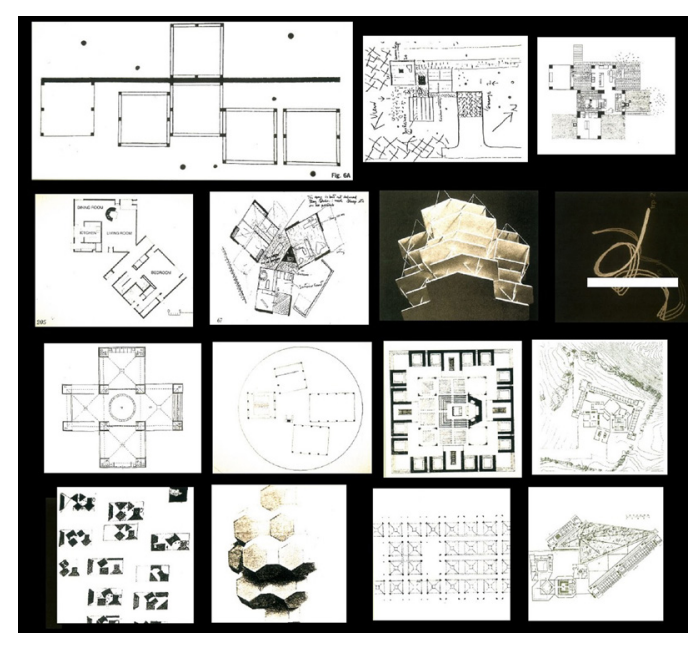

Figura 3: Baraja de plantas de la obra arquitectónica de Louis Kahn

Fuente: Juárez (2003, p. 91)

Evidentemente las cartas de Juárez para la entrevista no pretenden hacer de las obras de Kahn un "catálogo" o una simplificación de cómo acometía sus proyectos. Preferimos interpretar esta asociación con el juego desde la óptica de Sabini (1994):

Esto no significa que Kahn mirara la historia de la arquitectura como un catálogo a hojear y del cual sacar formas y figuras (...) la memoria de Kahn nunca dejó de ser rica en imágenes, pero siempre tendió a establecer nuevas, originales y significativas asociaciones, decía Kahn ya en 1955 (p. 19)

En cierto modo, llevándolo al ámbito del proyecto de arquitectura, en los juegos de cartas los integrantes de esta relación se van también a combinar al azar, regidos por unas reglas establecidas, generándose algunas situaciones y determinaciones análogas a las que se suceden al proyectar. Como referencia última, Huizinga en su libro en torno al juego, de obligada mención, aporta un interesante inventario de sus componentes: "tensión, equilibro, oscilación, contraste, variación, traba y liberación, desenlace" (1972, p.23). Para Huizinga "el juego puede ser muy bien algo serio" (1972, p.17), y en concreto:

(...) el juego de naipes se diferencia del que se vale del tablero porque en aquél no está excluido por completo el azar. En la medida en que es un juego de azar se halla en el mismo campo que el juego de dados, muy poco apropiado para la formación de clubes y para campeonatos públicos. Los juegos de cartas que exigen entendimiento permiten esta última derivación. El incremento del carácter serio se patentiza en este caso de manera extraordinaria. Desde I'hombre y la quadrille hasta el bridge, pasando por el whist, el juego de cartas sigue un proceso de refinamiento creciente; pero solo a partir del bridge la moderna técnica social se apodera del juego. Con sus manuales y sistemas, con sus grandes maestros y entrenadores, se ha convertido en la cosa más seria del mundo (Huizinga, 1972, p. 234)

En los textos de Metápolis, Juárez y Sánchez, estos componentes están implícitos. La incorporación en las cartas del inventario de Huizinga, al dibujar, construir o jugar a proyectar, refuerza la entidad de esta colección de juegos dentro del ámbito prestado de la arquitectura, en diferente medida podemos detectar su participación en los siete casos. En un análisis comparado, los aspectos a tratar serán: la condición didáctica, la intervención de la arquitectura y el rol de los componentes gráficos en el juego. No se ha considerado aplicar una metodología única o unos índices fijos al analizar los juegos. Dado el panorama heterogéneo de esta colección, la atención a estos aspectos será, en consecuencia, igualmente heterogénea.

En los apartados siguientes, al abordarlos individualmente, se plantea una obligadamente breve visión particular de cada uno, derivada fundamentalmente de su condición didáctica, sin detrimento de otras clasificaciones posibles que pudieran establecerse. Los juegos, según esta condición, se podrían dividir en las dos vías señaladas, iniciación y avanzada. La división de estas vías no solo es evidente en la concepción del diseño de las cartas, también se refleja en el proyecto de juego, en las reglas o en la intervención de parámetros o acciones propias de la arquitectura. Cada vía presupone una edad, o una formación más o menos especializada del jugador, pero en consonancia con lo difuso de las fronteras entre arquitectura y juego, estas distinciones de nivel no pretenden determinar límites, simplificar o acotar el uso del juego al nivel o la edad, sino poner en valor su idoneidad para un desarrollo formativo diferenciado en etapas, según la complejidad del juego y la preparación del jugador.

\section{Juegos de naipes, análisis y explicación}

Archicards, Scala, D'archis y House of Cards serán los juegos de iniciación (Figura 4). Podría establecerse una analogía con el uso pedagógico de otro ámbito alternativo, el cómic: "la desaprensión que se desprende del talante informal del cómic puede facilitar en el alumno su implicación afectiva con el conocimiento, considerado como un bien valioso y apreciado" (Arango, 2009, p.29). Este talante informal podría aplicarse también al naipe. El jugador ve en él un objeto de juego que ya le es familiar. El naipe, de igual manera que el cómic, podrá provocar una análoga implicación afectiva que facilitará el aprendizaje. Para incitar la implicación con el usuario en el tema específico de la arquitectura se recurrirá a dos componentes: un atrayente imaginario gráfico y el incitar a ejecutar dos operaciones básicas en el juego: construir y dibujar. Se facilita el entrar en la arquitectura al propiciar una predisposición sensorial ante la observación de las atractivas ilustraciones y el desarrollo de estas acciones creativas (Alba, 2018, p.18). Del imaginario gráfico se encargan Archicards, centrado en la figura y producción del arquitecto, y Scala, focalizada en obras notables del XX-XXI. De la iniciación mediante el dibujo y la construcción, $D$ 'archis y House of cards.

Al observar las imágenes de las ilustraciones de las cartas de Archicards y Scala el jugador se introduce en la cultura visual arquitectónica, mediante obras y arquitectos notables, con planteamientos diferentes en cada uno de ellos. El primer juego, Archicards, es un atractivo y bien documentado proyecto gráfico con formato de naipe. Su autor, Federico Babina, declara: "el juego también puede ser un experimento mental. Estoy interesado en jugar con 
la seriedad de la arquitectura y la ligereza de la ilustración" (Babina 2020). La seriedad y la ligereza se materializan con una selecta serie de trece arquitectos relevantes, modernos y contemporáneos. Con ellos construye un diseño de baraja. Cada arquitecto encarna a un rey y su imagen se configura con componentes de su obra. Un análisis previo de su arquitectura permite dar forma a sus retratos, con la incorporación de sus particulares simbologías formales se generan unas ilustraciones que los identifican. Archicards, aparte de contener una serie de buenas ilustraciones, podría verse como un óptimo reclamo que incita a profundizar en la obra del arquitecto representado. Cada carta dedicada a un arquitecto es una lección de aproximación al arquitecto. El diseño del naipe, con el retrato acompañado de significativos elementos formales característicos de su producción arquitectónica, ofrece una síntesis visual del arquitecto y su obra que, como señalaba Navarro Baldeweg (2016, p.9), propiciaría generar en el observador un territorio de expectativas que le desafiaría y pondría en marcha su curiosidad por aprender.

Scala, es una propuesta que forma parte la extensa obra gráfica del estudio Arquitectura a Contrapelo. Scala es una baraja francesa ilustrada con imágenes de arquitecturas contemporáneas, elegidas por los autores. Está formada por

proyectos divertidos, libres, que no categorizan, y que no redefinen la arquitectura comúnmente conocida, sino que la completan, complementan, la ponen del revés o de lado, la pintan de colores o la desnudan (...) nuestro «catálogo» es completamente subjetivo, y debe mucho a lo que hemos ido absorbiendo a lo largo de nuestros años de formación (Asensio, 2017, s.p.)

Scala "a través del dibujo refleja el panorama internacional de la arquitectura del siglo XXI. Cada naipe muestra una obra representativa del último cuarto de siglo y cada palo aglutina proyectos de escala similar, desde el pabellón o la casa hasta la infraestructura urbana" (Arquitectura a Contrapelo, 2020), con una heterogénea e interesante selección de cincuenta y dos obras, de arquitectos, como Aires Mateu, Alvaro Siza, John Pawson, Miralles\&Tagliabue o Herzog\&de Meuros, entre otros. El imaginario de Scala se conforma con obras ejemplares, resueltas con una estrategia gráfica propia, en la que se sintetizan las formas y se incide en la presencia de texturas y colores. Con estos recursos gráficos aplicados a arquitecturas diversas se proyecta este coherente diseño de baraja. La concepción gráfica común, rigurosa y atractiva, junto a la adecuada selección de obras, confirman también a Scala como un recurso para introducirse en la contemporaneidad arquitectónica. " $\mathrm{A} a \mathrm{C}$ es un proyecto compartido por Pedro Mena, Miguel Rabán y Juan Luis Romero, arquitectos por la ETSA de Sevilla, y concebido como lugar común en el que investigar y dar forma a otros modos posibles de llevar a cabo el ejercicio de la profesión" (Arquitectura a Contrapelo, 2020). Sobre Scala escriben:

nuestro proyecto se propone reunir el trabajo de los arquitectos más relevantes de nuestra época, y al mismo tiempo poner en valor trabajos en países emergentes para la crítica arquitectónica, todo ello reunido en un objeto cuidadosamente diseñado que cumple los parámetros tradicionales del juego de póker (Arquitectura a Contrapelo, 2020, s.p.)
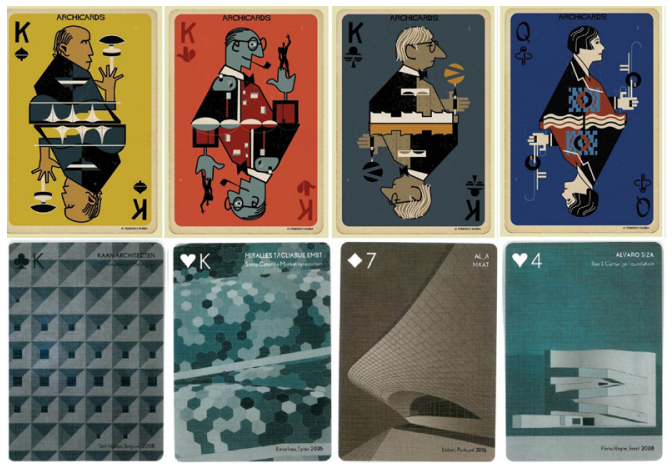

Figura 4: Juegos de iniciación. Selección aleatoria de cartas de Archicard y Scala

Fuente: Babina (2020), Arquitectura a contrapelo (2020)

Los casos de House of Cards y D'archis juegan con la creatividad y propician un papel activo en el jugador. Este ya no solo observa arquitectura, construirá y dibujará mientras juega (Figuras 5 y 6 ). En las series House of Cards, de los Eames, el objeto del juego es la acción de construir. Estas series se componen de unas atractivas cartas, en varios tamaños:

\section{(...) cada carta contiene seis cortes, uno en cada extremo y dos en cada lado, que hacían posible trabarlas entre sí para componer infinitas variantes arquitectónicas (...) y formar diversas estructuras tridimensionales, el castillo de naipes se convertía en un caleidoscopio de cartón de colores constantemente cambiante. Texturas, objetos domésticos o de la naturaleza - animal, vegetal y mineral-, aparatos científicos.. con ellos se crean las coloristas y eclécticas imágenes de las cartas, imágenes de "cosas buenas" recopiladas de muchas fuentes; objetos familiares y nostálgicos de los reinos animal, mineral y vegetal (Neuhart, 1989, p. 169)}

Unos motivos propios del optimista universo gráfico de los Eames, coleccionistas natos (Arcos, 2015, p.288). House of Cards forma parte de la amplia oferta de diseños de los Eames dirigidas al niño. Las series House of Cards serán juegos de cartas o de construcción, según decida el usuario (Koenig, 2006, p.63). Experimentar con "el juego como objeto y como metodología, el cambio de escala y el proceso de trabajo concatenado, lo individual en lo seriado, la importancia de lo cotidiano, de la colección y de la fotografía, (...), la celebración permanente y la conexión de la vida con el arte" (Fernández, 2019, p. 86). Las cartas se ilustran con cuidadas composiciones fotográficas de objetos que los Eames coleccionaban. En el dorso su característico asterisco resalta sobre un fondo blanco.

Los Eames proponen una serie de construcciones fotografiadas en las reglas, un catálogo de formas que muestra las posibilidades del juego para generar arquitecturas a diversas escalas: ciudad, iglesia, recinto, casa, puente, U.N., edificio, hangar, estadio, torre, arquería, casa divertida, tienda o cúpula. Junto a las múltiples formas construibles, se pueden proponer reflexiones en torno a conceptos de una cierta complejidad, como módulo, ritmo, serie, cerramiento, cubrición, ensamble, montaje... entre otros, que hacen de este juego un medio instructivo para conocer términos arquitectónicos que pueden ser construidos jugando con House of Cards, de forma sencilla, atractiva e incluso divertida. 

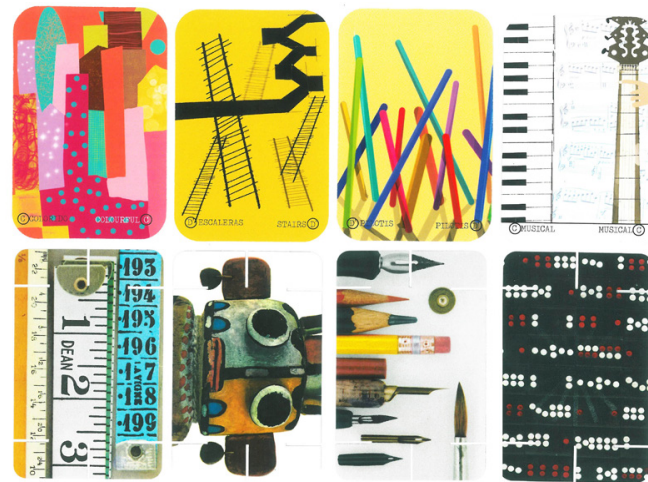

Figura 5: Juegos de iniciación. Selección aleatoria de cartas de D’archis y House of Cards

Fuente: Ruiz (2020), Eames (1986)

D'archis es un juego de cartas creado por Ángela Ruiz, arquitecta y profesora de la Escuela de Arquitectura de Madrid, para sus estudiantes de arquitectura y diseño. Un juego para

diseñadores, arquitectos, artistas, dibujantes, emprendedores, empresarios, profesionales o amateurs, niños, adolescentes, ancianos, adultos o combinaciones de ellos (...) el objetivo principal es CREAR, en cualquiera de las posibles formas de creación, para resolver el RETO CREATIVO que el azar encargue. Es posible crear dibujando, escribiendo, contando historias, cuentos, novelas, debatiendo ideas, oportunidades de negocio (Ruiz, 2020).

Las creaciones parten de un simulacro de la práctica de un arquitecto o diseñador, con retos de diseño por "encargos de clientes, concursos, puestos de trabajo, prácticas en empresa, colaboraciones de amistad o tiempos dedicados a la creación artística sin ánimo de lucro" (Ruiz, 2020, s.p.).

El juego se desarrolla en torno a temas que han de combinarse entre sí mediante el azar, para concebir relatos y dibujos. En el juego, el azar designa una serie de cartas, y esta serie genera situaciones que el jugador tendrá que resolver con dibujos y un breve texto. D'archis comparte la tesis de Gutiérrez (2004) sobre creatividad e imaginación: "cuando se revisan los escritos que relacionan la pedagogía y el juego, los diversos autores y enfoques dados al tema, todos coinciden en la importancia que el juego tiene en potenciar la imaginación y la creatividad" (p. 95). La arquitectura siempre tendrá presencia en el juego, combinada con otros temas: dispositivos, dinamizadores, conceptos, habitantes, instrucciones y situaciones. En la serie de cartas de arquitectura, se incluyen términos como: torre, habitación, parque, casa, vivienda, mueble o fábrica, entre otros. Estos serán los desencadenantes que habrá que enlazar con el resto de temas en los dibujos y relatos que se generen. Prima la búsqueda de propuestas creativas, que han de derivar de las coloristas, heterogéneas y atractivas ilustraciones de los naipes, todos dibujados por su creadora. D'archis es un estimulante recurso para crear debates sobre arquitectura en un aula de iniciación, mediante el papel activo del dibujo y el relato.

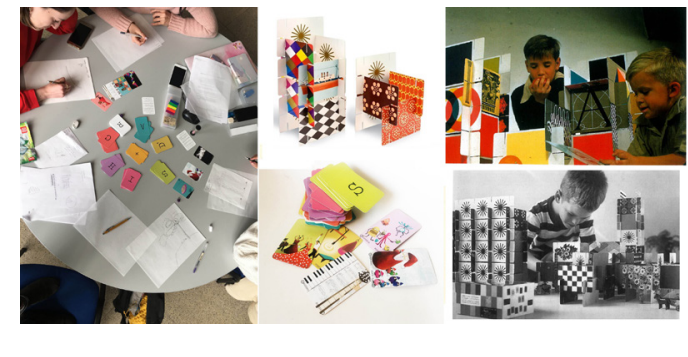

Figura 6: Juegos de iniciación, D'archis y House of Cards. Jugar, acciones: dibujar y construir Fuente: Ruiz (2020), Neuhart (1989, p.169)

50 Urban Blocks, 50 Housing Floor Plans y Modulark serán los juegos avanzados. Requerirán una mayor profundización disciplinar en el devenir del juego, lo que conllevará un diseño más especializado del naipe. En ellos la arquitectura no es solo ilustración o recurso formal: el juego reproduce prácticas extraídas de ella. Las reglas de juego son más complejas. A las cartas o juegos se le incorporan parámetros, códigos o acciones propios de la arquitectura, componentes que también intervienen en los procesos constructivos, el diseño de edificaciones o la práctica profesional, entre otros. Se opera con más datos y relaciones. Son solo juegos, pero la apariencia de realidad se acentúa. Se aprecia en ellos una relación más intensa con el contenido de los textos de referencia: mayor presencia de tensión, equilibrio, oscilación, contraste, variación, traba y liberación, desenlace, o del proyecto como acto de conjuntar la diversidad de modo impredecible, desde un azar controlado por sistemas y reglas eficaces, atractivas y solo parcialmente previsibles.

El equipo $\mathrm{a}+\mathrm{t}$ architecture y el colectivo Straddle3 son los creadores de estas cartas. Los tres juegos divergen en el tipo de arquitectura en el que se desarrollan. Straddle3 y $\mathrm{a}+\mathrm{t}$ architecture publishers tendrán posiciones diferenciadas, pragmatismo en $\mathrm{a}+\mathrm{t}$ architecture, frente al idealismo y disidencia en Straddle3. La principal diferencia entre ellos estará en la gestión del proyecto: medios convencionales y vías dentro de lo establecido frente a la disidencia, la autogestión y la auto-construcción, pero también compartirán aspectos como sostenibilidad o calidad de vida. Muestra de esas diferentes posiciones serán los componentes que condicionan los juegos (Figura 7)

En 50 Urban Blocks, se utilizan parámetros como tipologías, densidad, edificabilidad y ocupación. En 50 Housing Floor Plans los parámetros son: tipologías, porcentaje de espacio exterior, porcentaje de fachada, grado de privacidad, índice de circulación, en cuatro tamaños de vivienda según la superficie. En Modulark juegan con procesos constructivos auto-gestionados por los futuros usuarios, con parámetros como: contenedores, envolventes, energía, soporte vital o acciones.

50 Urban Blocks y 50 Floor Plans, pertenecen a una serie de publicaciones de $a+t$ architecture publishers, denominada Densidad, con la que analiza proyectos de vivienda colectiva en relación con la densidad de la ciudad. 
at architecture publishers es una editorial especializada en publicaciones de arquitectura, independiente y ajena a cualquier institución o colectivo profesional. Fundada en 1992 en Vitoria-Gasteiz (...) Su objetivo es difundir sus investigaciones en vivienda colectiva, densidad, usos mixtos y espacio público a través de a+t architecture publishers (... Pero las preocupaciones siguen siendo las mismas: la vivienda asequible, la densidad, la mezcla de usos, la privatización del espacio urbano (Aplust, 2020, s.p.).

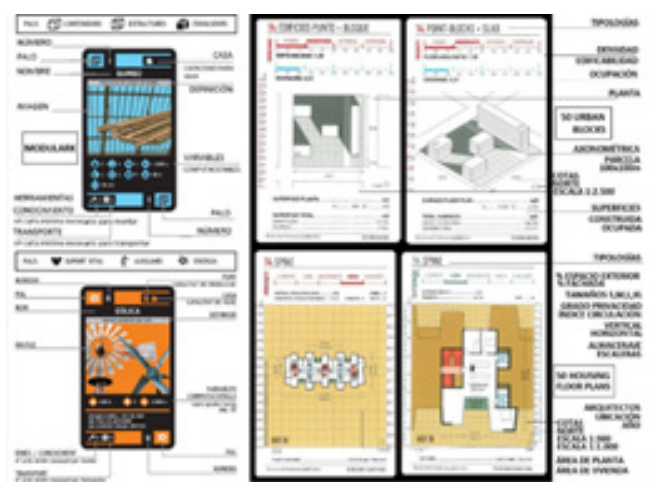

Figura 7: Diseño de las cartas de Modulark, 50 Urban Blocks y 50 Housing Floor Plans, parámetros y datos para el juego con la arquitectura. Elaboración del autor

Fuente: Aplust (2020), $a+t$ (2017), $a+t$ (2018) Straddle3(2020)

50 Urban Blocks y 50 Housing Floor Plans son básicamente unos catálogos de casos en los que se combinan los parámetros que rigen los dos juegos, a dos escalas diferentes, la urbana y la edificatoria (Figura 8).

En 50 Urban Blocks, sus autores plantean diversas formas urbanas desde la unidad de la manzana, una invariante de forma cuadrada de 100×100 metros, sobre la que se insertan "50 formas de construir la ciudad, 50 reflexiones sobre el uso del territorio, 50 intentos de conseguir la manzana ideal...infinitas maneras de imaginar la ciudad" (Aplust, 2020), mediante 50 diseños en planta y volumen de cada propuesta. 50 Housing Floor Plans es un inventario de viviendas de proyectos recientes, ordenados por su grado de privacidad y el índice de espacio no habitable ocupado por las circulaciones, que determinan su grado de aprovechamiento. Sus autores señalan: "es nuestra apuesta por difundir la vivienda colectiva en la que desearíamos vivir. No es una baraja para jugar. Es una baraja para vivir mejor" (Aplust, 2020). Proponen "ofrecer soluciones imaginativas que combinen exterioridad y privacidad" (Aplust, 2020). Según se especifica en sus reglas "la colección de cartas resulta especialmente útil para estudiantes y jóvenes arquitectos que necesiten inspiración en sus primeras aproximaciones al proyecto arquitectónico" (Cinqpoints, 2020). El arquitecto o estudiante de arquitectura será el potencial usuario de estos dos juegos. Para ellos se conforman estos catálogos de soluciones posibles. Sus conocimientos, más o menos avanzados, les permitirán seleccionar, desechar o combinar razonadamente las propuestas. 50 Urban Blocks y 50 Floor Plans, juegan con la combinación, con búsqueda de soluciones diversas ante unas mismas condiciones de partida. Esta combinación puede ser ordenada seleccionando la propuesta que se considere mejor, o también podría plantearse dejarse llevar por el juego y "conjuntar la diversidad de modo impredecible. Quizás a alguien se le ocurra que esto tiene que ver con cierta imagen de cómo se desarrolla el juego (...) Se trata de un juego que formula sus nuevas leyes en cada tirada, en cada jugada" (Gausa et al., 2002, p. 352), y el jugador decide la opción a seguir.

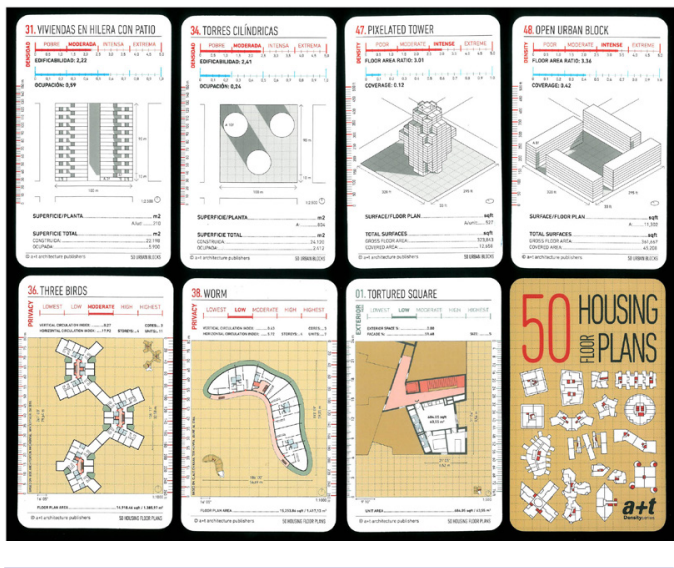

Figura 8: Selección aleatoria de cartas de 50 Urban Blocks y 50 Housing Floor Plans

Fuente: Aplust (2020), a+t (2017), a+t (2018)

Modulark fue creado en 2008 por el colectivo de arquitectura Straddle3, una organización aun en activo, que desde 1998 trabaja temas de arquitectura y ciudad desde la acción directa y la autogestión. Modulark es un

juego de cartas didáctico que permite experimentar formas de creación y autogestión de proyectos autónomos, a través de elementos constructivos y de apoyo vital (...) mediante procesos de participación ciudadana sobre recuperación de tejido industrial y cultural, intervenciones temporales y permanentes en espacios y edificios públicos, o casos de autoconstrucción a partir de materiales reciclados... Somos un colectivo activo en Barcelona desde 1998 que trabajamos temas de arquitectura y ciudad desde la autonomía y la acción directa. Desarrollamos procesos de participación ciudadana sobre recuperación de tejido industrial y cultural intervenciones temporales y permanentes en espacios y edificios públicos, o casos de autoconstrucción a partir de materiales reciclados (Straddle3, 2020, s.p.)

El juego de cartas es un recurso más dentro de su actividad. De disponibilidad abierta, es un juego consecuente con su manera de ejercer la arquitectura" (Figura 9).

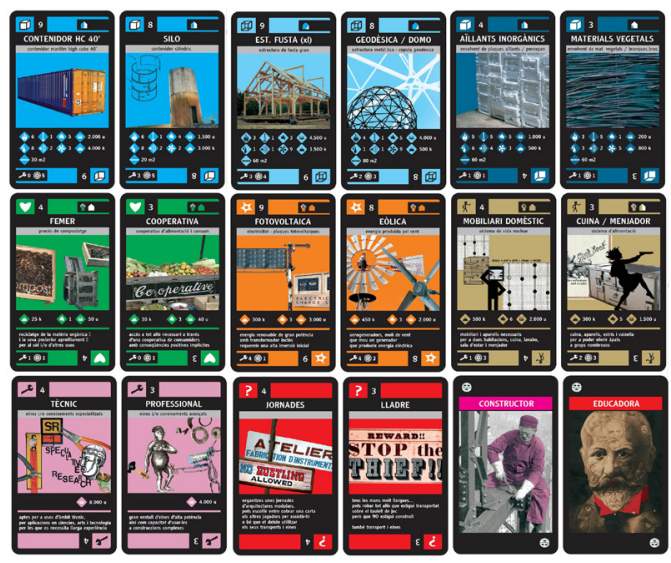

Figura 9: Selección aleatoria de cartas del juego Modulark Fuente: Straddle3 (2020) 
Modulark es una materialización de la forma de proyectar arquitectura de Straddle3. Se trata de construir proyectos constructivos auto-gestionados por el jugador, con elementos de arquitectura modular, relaciones de código abierto entre los participantes y factores de supervivencia y sociales, que han de ir sorteándose en la partida. Las cartas se estructuran en familias que regulan el juego: contenedores, estructura, envolventes, energía, soporte vital, auxiliares, transporte, herramientas/ conocimientos y acciones. Participan en la partida hasta seis jugadores, a los que se les pide colaboración y cooperación para crear cada uno de ellos un espacio en el que poder vivir y producir, bajo unas condiciones mínimas establecidas en las cartas. Modulark, en coherencia con sus planteamientos, es un recurso asequible sin costo, de "código abierto", que permite desarrollar proyectos según los métodos característicos de Straddle3.

\section{Conclusiones}

Como se señalaba en el texto de referencia de Juárez (2003), una operación como el conformar una baraja con plantas escogidas de Louis Kahn, y verterla sobre un tapete, permite fijar la atención en cómo la aleatoriedad y el azar hacen que "estos proyectos adquieren una singular belleza. (...) entre lo ordenado y lo aleatorio, y esta síntesis nos revele algo profundo y apasionante de su modo de proyectar" (p. 90). Aunque también pudiera ser interpretado en forma contraria, como un acto sin mayor trascendencia, ni relación alguna con la arquitectura representada. Entre valorar o devaluar estas cartas, nos posicionamos en una prudente situación intermedia, estimando aquello que las relaciona seriamente con la arquitectura. En la combinación de estos siete juegos en una interzona delimitada por juego, arquitectura y didáctica, se confirma, al menos, el ser recursos competentes para iniciarse, experimentar o crear arquitectura, mientras se juega, se construye, se dibuja y se proyecta o, simplemente, se observa su seductor imaginario visual. Serán unos objetos "provocadores de experiencias" (Bordes, 2016, p. 59), que facilitan una "predisposición sensorial" (Alba, 2018, p. 19) del jugador ante la arquitectura a través de la vista y la ejecución de acciones plásticas.

Un uso creativo de los juegos contribuirá también al acercamiento a esta disciplina de un posible jugador general ajeno a ella. Para este, de la misma manera que jugando con los juegos de dibujo o construcción que recopila Bordes, un objetivo al jugar será "formar mentes de personas creativas que también se han dispersado en otras profesiones distintas al tema de estos juegos" (Bordes, 2016, p. 59).

En los juegos de iniciación, la interacción del jugador iría desde la observación e interpretación de las ilustraciones, en Archicards y Scala, a la participación activa, dibujando, narrando o construyendo formas en D'archis y House of Cards. En estos juegos no es necesaria una formación arquitectónica previa, de ahí su carácter iniciático. Señalábamos su condición ambivalente. Su mayor o menor implicación formativa se desarrolla según lo que se pretenda de ellos, o según el nivel de jugador. Es opción del docente graduar la intervención de la arquitectura y hacer un uso especializado. Sirva como ejemplo House of Cards. Un niño puede iniciarse en la arquitectura construyendo un castillo con sus atractivas y coloristas cartas, "un caleidoscopio de cartón de colores e imágenes constantemente cambiantes" (Fernández, 2019, p.92). Un estudiante de arquitectura puede establecer analogías con la arquitectura modular, prefabricada y estandarizada de los Eames. Los dibujos y relatos con $D^{\prime}$ archis puede ser más o menos complejos, de igual forma que el debate sobre las ilustraciones de Scala o Archicards puede ser más o menos disciplinar. En el aula se decide hasta dónde se llega, el nivel condiciona, pero no impide el desarrollo del juego, desde lo más básico, como simple diversión, hasta ser medios capaces de fomentar un aprendizaje de la disciplina.

En los juegos más avanzados se requiere formación en arquitectura en el jugador. Las partidas serán simulaciones o remedos de la práctica real, pero al actuar o decidir no habrá mayores consecuencias que las que quedan en el tablero. Realidad y juego se diferencian, "Ias cosas que requieren una maduración lenta no se dejan ludificar. La duración y la lentitud no son compatibles con la temporalidad del juego" (Byung-Chan, 2014, p.78). Su condición de juegos los circunscribe a ser "una acción que se desarrolla dentro de ciertos límites de tiempo, espacio y sentido, en un orden visible, según reglas libremente aceptadas y fuera de la esfera de la utilidad o de la necesidad de materiales" (Huizinga, 1972, p.157). Conscientes de todo ello, al interpretarlos se opta por evitar disquisiciones desmedidamente trascendentes e implicadas en exceso con la práctica del proyecto, ni tampoco aplicarles una concreta metodología de análisis, sin que esto sea impedimento para razonar y también jugar, con un cierto desprejuicio, a compararlos y detectar sus aciertos en el modo de intervención de la arquitectura de forma conjunta, antes que particularizada en algún juego, asumiendo las diferencias entre ellos.

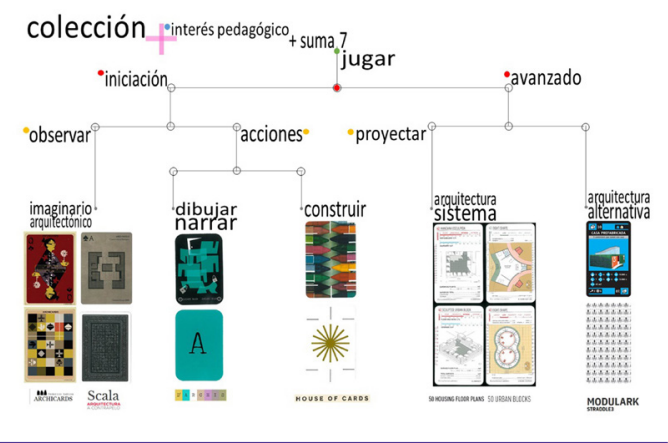

Figura 10: Esquema gráfico ordenado de la colección de juegos de cartas. Jugar en iniciación: observar imaginario arquitectónico y acciones, dibujar y construir. Jugar avanzado: proyectar arquitectura desde parámetros convencionales a alternativos. En orden de izquierda a derecha: Archicards, Scala, D'archis, House of Cards, 50 Urban Blocks, 50 Housing Floor Plans y Modulark

Fuente: Babina (2020), Arquitectura a contrapelo (2020), Ruiz (2020), Eames (1986) Aplust (2020), a+t (2017), a+t (2018), Straddle3 (2020)

Nada más lejos de la intención del análisis conjunto que atribuir a los juegos una "simplista positividad" (Massad, 2018, p. 38), o ver en ellos propiedades desmesuradas y superiores a las enunciadas. Es valorable en ellos, fundamentalmente el potencial emotivo y motivacional 
(Moreno, 2011, p. 5) de unos recursos analógicos, insertos en un proceso formativo complejo en el que prima lo digital (Sentieri, 2018, p. 120). En una posición mucho más modesta, esta colección (Figura 10) comparte algunas de las finalidades que señala Bordes (2016) sobre su colección de juguetes de construcción, entre las que destaca que "el desarrollar una mente creativa y estructurada arquitectónicamente es deseable y útil para todas las profesiones" (p. 59). Como se advertía al inicio, sobre el valor coral de las colecciones y la búsqueda de un discurso común, se puede afirmar que "rocas, animales, plantas, imágenes, estampillas, edificios, partes de edificios, ciudades, todos son material potencial para un coleccionista" (Celedón, 2015, p. 44). Esta recopilación de casos arquitectónicos también tendrá ese potencial, como un competente recurso formativo conjunto de siete opciones diferentes, adecuadas al interés o nivel de conocimiento del jugador.

Cómo citar este artículo/How to cite this article: Bravo de Laguna Socorro, A. (2021). Colección de juegos de cartas de arquitectura. Siete recursos para iniciación, creatividad o experimentación avanzada. Estoa. Revista de la Facultad de Arquitectura y Urbanismo de la Universidad de Cuenca, 10(19), 115-125. doi: 10.18537/est.v010 n019.a10

\section{Referencias bibliográficas}

a+t research group (Ed.) (2017). 50 Urban Blocks: a+t architecture publishers.

a+t research group (Ed.) (2018). 50 Housing Floor Plans. $\mathrm{a}+\mathrm{t}$ architecture publishers.

Alba, M. (2018). Estrategias formativas en la iniciación del aprendizaje del proyecto arquitectónico. Estoa. Revista de la Facultad de Arquitectura y Urbanismo de la Universidad de Cuenca, 7(14), 17-29. https://doi. org/10.18537/est.v007.n014.a01

Aplust (2020, 24 de junio). https://aplust.net

Arango, J. A., Gómez Salazar, L. E. y Gómez Hernández, M.M. (2009). El cómic es cosa seria. El cómic como mediación para la enseñanza en la educación superior Anagramas, 7 (14) 13-32. https://doi.org/10.22395/angr. v7n14a1

Arcos, C. C. (2015). Arquitectura+Juego (Los años pop 1959-1967 [Tesis doctoral, Universidad Politécnica de Madrid]. http://oa.upm.es/40738/

Arnau, J. (2000). 72 Voces para un diccionario de Arquitectura Teórica. Celeste Ediciones.

Arquitectura a contrapelo (2020, 24 de junio). https:// arquitecturaacontrapelo.es
Asensio, A. (2017). Scala/Ilustración, juego y arquitectura. AAAA magazine. https://theaaaamagazine.wordpress. com/2017/02/13/scala-ilustracion-juego-y-arquitectura/

Babina, F. (2020). http://www.federicobabina.com /2020

Bernadó, J. (Coord.) (1997). Áreas de impunidad. Ábalos \& Herreros. Actar.

Bordes Caballero, J. (2011). Jugando a construir la vanguardia: los juguetes comerciales en el siglo XIX derivados de programas educativos. En J. Lebrero (Dir.), Los juguetes de las vanguardias (pp.9-53). Museo Picasso.

Bordes Caballero, J. (2016). Construir una historia: una colección sin protagonista. En J. Bordes Caballero (Ed.) Juguetes de construcción. Escuela de la Arquitectura Moderna (pp.23-59). Círculo de Bellas Artes de Madrid.

Byung-Chan, H. (2014) Psicopolítica. Neoliberalismo y nuevas técnicas de poder. Herder.

Celedón, A. (2015). Gabinetes de la ciudad. Revista 180 (36) 42-47. http://dx.doi.org/10.32995/rev180.Num-36 (2015).art-24

Cinqpoints (2020, 24 de junio). https://cinqpoints.com

Eames, C. y Eames, R. (1986). House of Cards. Picture Deck. Eames Office

Fernández Villalobos, N. (2019). House of Cards: E "continente". Eames en una baraja de cartas. Proyecto, Progreso, Arquitectura (20), 86-105.

Gausa, M., Guallart, V., Muller, W., Morales, J., Porras, F. y Soriano, F. (2002). Diccionario Metápolis de Arquitectura Avanzada. Actar.

Gutiérrez Párraga, M.T. (2004). La significación del juego en el arte moderno y sus implicaciones en la educación artística [Tesis doctoral, Universidad Complutense de Madrid]. https://eprints.ucm.es/7209/

Huizinga, J. (1972). Homo Ludens. Alianza Editorial.

Juárez, A. (2003). Aleatoriedad y orden en la arquitectura de Louis Kahn, ViA arquitectura, Cajas, (03), 91-97.

Koenig, G. (2006). Eames. Taschen.

Massad, F. (2018) Crítica de Choque. Qutediciones.

Moreno B., López-Crespo, P. y Moya, M. V. (2011). Propuesta de una herramienta didáctica basada en un juego de cartas para el estudio de propiedades de materiales. Actas Congreso Internacional de Innovación docente Universidad Politécnica de Cartagena (pp. 539547). Universidad Politécnica de Cartagena.

Navarro Baldeweg, J. (2016). Una caja de cajas. En J. Bordes Caballero (Ed.), Juguetes de construcción. Escuela de la Arquitectura Moderna (pp. 9-11). Círculo de Bellas Artes. 
Neuhart, J., Neuhart, M. y Eames, R. (1989). Eames Design. The work of the Office of Charles and Ray Eames. Harry N. Abrams, Inc., Publishers

Real Academia Española. (2020). Diccionario de la lengua española (edición del tricentenario). https://dle.rae.es

Ruiz, Á. (2020). D'archis. Creatividad al poder en tu bolsillo. https://darchisgame.com/ 2020.

Sabini, M. (1994). Louis I. Kahn y el libro cero de la arquitectura. En V.V.A.A, Louis I. Kahn, Estudios Críticos (p.19). Ediciones del Serbal.

Sánchez Llorens, M. (2015). Lina Bo Bardi: Objetos y acciones colectivas. Diseño.

Sentieri, C. y Navarro, A. (2018) El aprendizaje de la arquitectura a través del juego. En D. García y B. Bardí (Eds.), Textos de Arquitectura, Docencia e Innovación (pp.116-133). RU Books.

Straddle3 (2020, 24 de junio). https://straddle3.net/es/ recursos/modulark

Vizcaíno, M. (2015). Área poco clara. Revista 180, (36), 2. 